\title{
The growth performance and immunity of broiler chickens affected by dietary chitosan oligosaccharides
}

\section{Hang Zhao}

Huaihai Institute of Technology

Saikun Pan ( $\nabla$ psklyg@sina.com )

Huaihai Institute of Technology

\section{Research}

Keywords: chitosan; oligosaccharide; growth; immunity

Posted Date: March 19th, 2020

DOI: https://doi.org/10.21203/rs.3.rs-17914/v1

License: (c) (i) This work is licensed under a Creative Commons Attribution 4.0 International License.

Read Full License 


\section{Abstract}

Background: The present study aimed to explore the effects of dietary chitosan oligosaccharides (COs) on the growth performance and immunity of broiler chickens.

Methods: Four test diets were supplemented with different doses of $\operatorname{COs}(0,50,100$ and $150 \mathrm{mg} / \mathrm{kg})$ and formulated. Triplicate groups of broiler chickens were fed with one of the diets ad libitum for 6 weeks.

Results: After the end of the feeding trials, oral $\mathrm{CO}$ administration improved average daily gain; the activities of digestive amylase, lipase and protease; the activities of serum superoxide dismutase and glutathione peroxidase; serum tumor necrosis factor-a, interleukin (IL)-1, IL-2, IgG, IgM and IgA levels; and reduced feed conversion ratio and malondialdehyde level compared with those of the control group. However, a high dose of $\mathrm{CO}(150 \mathrm{~g} / \mathrm{kg})$ did not further increase its efficiency compared with the moderate dose of $\mathrm{CO}(100 \mathrm{~g} / \mathrm{kg})$.

Conclusions: Oral $\mathrm{CO}$ administration improved the growth performance and immunity of juvenile broiler chickens and could be used as a feed supplement.

\section{Introduction}

Chitin is a homopolysaccharide formed of $\beta$-1,4-linked N-acetyl-D-glucosamine units in algae, shrimps, crabs, marine diatoms, insects and fungi. Chitosan, a biopolymer composed of primary 2-amino-2-deoxyd-glucopyranose (GIcN) and trace N-acetyl D-glucosamine units, is derived from chitin by demineralisation, deproteinisation, deacetylation and decolouration [1].

Chitosan oligosaccharides (COs) are oligomers of GlcN and have traces of 2-acetamido-2-deoxy-dglucopyranose. COs possess many special physical, chemical and biological properties, such as antioxidant, antibacterial, antidiabetic, hypolipidemic and immunomodulatory activities [2-6]. Diets supplemented with COs effectively promoted the growth performance of koi, Japanese quail, turbot, sea cucumber, tiger puffer, weaned pigs and loach [7-13]. However, data on the effects of COs on the growth performance and immunity of broiler chickens are limited.

These data indicated that COs may affect the growth performance and immunity of broiler chickens, which is worthy of investigation. Thus, this work aimed to investigate the effects of dietary $\mathrm{CO}$ supplementation on the growth performance and immunity of broiler chickens.

\section{Materials And Methods}

\section{Materials}

COs were prepared in accordance with the methods of Wu [14]. The yield of $\mathrm{CO}$ and CO content in the product were $91.37 \%$ and $95.84 \%$, respectively. The enzyme-linked immunosorbent assay (ELISA) kits 
were purchased from Nanjing Jiancheng Bioengineering Institute (Nanjing, China). All other chemicals were of reagent grade.

\section{Diet preparation}

The nutrient composition of the basal diet for broiler chickens is presented in Table 1.The basal diet was supplemented with different levels of COs (50, 100 and $150 \mathrm{mg} / \mathrm{kg}$ dry diets) as three treatment groups, whilst the basal diet without added $\mathrm{CO}$ was used as the control diet. All ingredients were fully mixed with appropriate amounts of tap water, extruded, cut into particles, hot air-dried and stored at $\sim 25^{\circ} \mathrm{C}$.

\section{Broiler chicken feeding}

Ametal cage $(1.0 \mathrm{~m} \times 1.0 \mathrm{~m} \times 0.5)$ equipped with a nipple drinker was used as breeding equipment. Before the feeding trial, 144 Arbor Acre broiler chickens (1day old and mixed sex) were randomly distributed to 12 cages, resulting in 12 broiler chickens per cage and three cages per group. The broiler chickens in the control group were fed with a diet without $\mathrm{CO}$, whilst those in the three treatment groups were fed with a diet supplemented with 50,100 and $150 \mathrm{mg} / \mathrm{kg} \mathrm{CO}$. Feed and water were supplied ad libitum for all broiler chickens during the entire feeding trial period. All broiler chickens were individually marked.

The rearing temperature was set at $\sim 32^{\circ} \mathrm{Cin}$ the first week and reduced by $3^{\circ} \mathrm{C}$ weekly until $20^{\circ} \mathrm{C}$ was reached and maintained until the end of the experiment. During the whole feeding trial period, $23 \mathrm{~h} \mathrm{light}$ and $1 \mathrm{~h}$ dark illumination schedule was provided. Indoor sanitation was maintained by cleaning the cage and washing the drinking fountains daily. The incidence of death of the broiler chickens was recorded every day.

\section{Growth}

At the end of feeding trial, the broiler chickens from each cage were weighed. Growth performance was determined in accordance with the body weight gain of surviving broiler chickens in each cage and was calculated using the formula as follows: (final body weight - initial body weight)/day. Feed conversion ratio (FCR) was calculated in accordance with the following formula: food intake/body weight gain.

\section{Sampling}

At the end of feeding trial, three broiler chickens per cage were randomly selected and slaughtered, and their blood was collected to prepare serum samples. The serum was prepared from the blood samples by centrifugation at $2000 \times \mathrm{g}$ and $3{ }^{\circ} \mathrm{C}$ for $20 \mathrm{~min}$. Duodenal chyme was also collected. The serum and duodenal chyme samples were stored at $-75^{\circ} \mathrm{C}$ until use. The serum samples were used to analyse the levels of superoxide dismutase (SOD), glutathione peroxidase (GPx) and malondialdehyde (MDA), tumor necrosis factor (TNF)-a, interleukin (IL)-1, IL-2, IgG, IgM and IgA. The duodenal chyme samples were used to determine the activities of protease, amylase and lipase. 


\section{Assay methods}

Biochemical indices, such as the activities of protease, amylase, lipase, SOD and GPx, as well as the levels of TNF-a, IL-1 and IL-2, were determined using ELISA kits following the manufacturer's instructions. MDA was determined using kits (Solarbio, Beijing, China) in accordance with the manufacturer's instructions.

The levels of serum IgG, IgM and IgA were assayed through immunoturbidimetry by using an automatic biochemical analyser (Hitachi 7600, Japan). The kit was purchased from Weifang 3VBio-engineering Group Co., Ltd.

\section{Statistical analysis}

All tests were performed in triplicate, and data were reported as mean \pm standard deviation. The variance and significant differences amongst the means were tested through one-way ANOVA using SPSS software (version 17.0 for Windows, SPSS Inc., Chicago, IL, USA).

\section{Results}

\section{Growth performance}

At the end of the feeding trial, although no significant differences in Feed intake ( $\mathrm{FI}$ ) and survival rate were observed amongst all groups, dietary $\mathrm{CO}$ supplementation improved the average daily gain (ADG) of broiler chickens and decreased FCR compared with those of the control group (Table 2, $p<0.05$ ). However, the efficiency of high-dose $\mathrm{CO}$ supplementation $(100 \mathrm{mg} / \mathrm{kg})$ was reduced compared with that of the moderate-dose one $(150 \mathrm{mg} / \mathrm{kg}, p<0.05)$.

\section{Intestinal digestive enzymes}

The changes in the activities of digestive protease, amylase and lipase at the end of the feeding trial are presented in Table 3. Dietary CO supplementation significantly improved the activities of digestive protease, amylase and lipase compared with those of the control group $(p<0.05)$. Nevertheless, a high dose of CO $150 \mathrm{mg} / \mathrm{kg}$ ) could not further improve the activities of protease, amylase and lipase compared with the moderate group $(100 \mathrm{mg} / \mathrm{kg})$.

\section{Serum biochemical parameters}

The effects of dietary CO supplementation on the activities of serum SOD and GPx and the serum MDA level of broiler chickens at the end of feeding trial are presented in Table 4. The SOD and GPx activities of broiler chickens fed with a diet with $\mathrm{CO}$ were higher and their serum MDA level was lower than those of the control group ( $p<0.05)$. However, a high dose of $\mathrm{CO}(150 \mathrm{mg} / \mathrm{kg})$ could not further improve diet efficiency of COs compared with those in the group fed with moderate levels of $\mathrm{CO}(100 \mathrm{mg} / \mathrm{kg})$.

\section{Serum TNF- $a$, IL-1 and IL-2 levels}


At the end of the feeding trial, dietary CO supplementation improved serum TNF-a, IL-1 and IL-2 levels compared with those of the control group (Table 5, $p<0.05$ ). Nevertheless, a high dose of added CO (150 $\mathrm{mg} / \mathrm{kg}$ ) could not further improve TNF- $a$, IL-1 and IL-2 levels compared with those in the moderate group $(100 \mathrm{mg} / \mathrm{kg})$.

\section{Serum IgG, IgM and IgA levels}

The changes in serum IgG, IgM and IgA levels of the broiler chickens fed with CO-containing and control diets at the end of feeding trial are presented in Table 6. The IgG, IgM and IgA levels in the serum of broiler chickens fed with CO-containing diets were higher than those in the control group $(p<0.05)$. However, the differences in serum IgG, IgM and IgA levels of broiler chickens fed with high dose (150 $\mathrm{mg} / \mathrm{kg})$ and moderate dose $(100 \mathrm{mg} / \mathrm{kg})$ of feed with added CO were not significant $(p>0.05)$.

\section{Discussion}

Digestive protease, amylase and lipase can effectively hydrolyse protein, starch and lipids into molecules small enough to be effectively absorbed by the intestinal mucosa. In the present study, the ADG of the broiler chickens fed with COs was higher than that in broiler chickens fed with control diet, whilst FCR presented the opposite trend. This result could be attributed to the increased activities of protease, amylase and lipase. Similarly, dietary CO supplementation effectively improved the growth performance of koi, Japanese quail, turbot, sea cucumber, tiger puffer, weaned pigsandloach [7-13].

Intestinal digestive enzymes, including protease, amylase and lipase, play important roles in utilising protein, starch and lipids; therefore, evaluation of these enzymatic activities is pivotal in the poultry rearing industry [14-16]. Broiler chickens fed with a diet supplemented with $\mathrm{CO}$ showed higher intestinal digestive protease, amylase and lipase activities than the broiler chickens in the control group. Hence, $\mathrm{COs}$ induced the expression of such enzymes. Similarly, dietary CO supplementation effectively improved the digestive enzymatic activities of tiger puffer and loach $[9,13]$.

Dietary CO supplementation improved SOD and GPx activities in broiler chickens compared with those of broiler chickens in the control group. The MDA levels in the serum of broiler chickens whose diet was supplemented with $\mathrm{CO}$ were lower than those of broiler chickens in the control group; this result could be due to the antioxidant activities of COs [3]. Similarly, dietary CO supplementation increased SOD and GPX activities in koi, turbot, sea cucumber, weaned pigs and loach $[7,8,11-13]$.

Inflammation can be decreased via the up-regulation of anti-inflammatory cytokines [18]. In the present study, dietary CO supplementation improved serum TNF-a, IL-1 and IL-2 levels in broiler chickens compared with those in the control group; thus, dietary $\mathrm{CO}$ supplementation can reduce inflammation amongst broiler chickens; this phenomenon could be attributed to the antibacterial and immunomodulatory activities of $\operatorname{COs}[5,14]$. 
The broiler chickens fed with a diet supplemented with CO showed higher serum IgG, IgM and IgA levels compared with broiler chickens in the control group; this phenomenon could be due to the immunomodulatory activity of FAs ( [5]. Similarly, dietary CO supplementation increased the immunity of koi, turbot, sea cucumber, weaned pigs and loach [7, 8, 11-13].

\section{Conclusions}

Dietary CO supplementation improved ADG; the activities of digestive amylase, lipase and protease; the activities of serum SOD and CAT; serum TNF-a, IL- 1, IL-2, IgG, IgM and IgA levels; and reduced FCR and MDA level compared with the diet without $\mathrm{CO}$. Based on the effects of various $\mathrm{CO}$ doses on the growth performance, the optimum dose was $100 \mathrm{mg} / \mathrm{kg}$. Thus, COs could be used as an immunostimulant for juvenile broilers.

\section{Declarations}

\section{Acknowledgements}

This research was supported by A Project Funded by the Priority Academic Program Development of Jiangsu Higher Education Institutions (PAPD).

\section{Availability of data and materials}

The data used to support the findings of this study are included within the article.

\section{Authors' contributions}

Hang Zhao carried out the experiments, performed statistical data analysis. Saikun Pan designed and supervised the experiments. All authors have read and approved the final manuscript.

\section{Ethics approval}

This study was approved by the ethics committee of the Jiangsu Ocean University, China. All procedures were conducted in compliance with relevant laws and institutional guidelines.

\section{Competing interests}

The authors declare that they have no competing interests.

\section{References}

[1] Keser O, Bilal T, Kutay HC, Abas I, Eseceli H., Effects of chitosan oligosaccharide and/or Beta-glucan supplementation to diets contained organic zinc on performance and some blood indices in broilers. Pak. Vet. J. 2011;32:15-19. 
[2] Katiyar DM, Singh B, Lall AM, Haldar C. Evaluation of antidiabetic and hypolipidemic activity of chitooligosaccharides in alloxan-induced diabetes mellitus in mice. Int. J. Pharma. Bio Sci. 2011;2:407416 .

[3] Laokuldilok T, Potivas T, Kanha N, Surawang S, Seesuriyachan P, Wangtueai S, et al. Physicochemical, antioxidant, and antimicrobial properties of chitooligosaccharides produced using three different enzyme treatments. Food Biosci. 2017;18:28-33.

[4] Wu SJ. Preparation of chitooligosaccharides from Clanis bilineata larvae skin and their antibacterial activity. Int. J. Biol. Macromol. 2012;51:1147-1150.

[5] Xing R, Liu Y, Li K, Yu H, Liu S, Yang Y, et al. Monomer composition of chitooligosaccharides obtained by different degradation methods and their effects on immunomodulatory activities. Carbohydr. Polym. 2017;157:1288-1297.

[6] Xia Z, Chen J, Wu S. Hypolipidemic activity of the chitooligosaccharides from Clanis bilineata (Lepidoptera), an edible insect. Int. J. Biol. Macromol. 2013;59:96-98.

[7] Cui LQ, Xu W, Ai QH, Wang DF, Mai KS. Effects of dietary chitosan oligosaccharide complex with rare earth on growth performance and innate immune response of turbot, Scophthalmus maximus L. Aquac. Res. 2013;44:683-690.

[8] Lin S, Mao S, Guan Y, Luo L, Luo L, Pan Y. Effects of dietary chitosan oligosaccharides and Bacillus coagulans on the growth, innate immunity and resistance of koi (Cyprinus carpio koi). Aquaculture. 2012;342-343:36-41.

[9] Su P, Han Y, Jiang C, Ma Y, Pan J, Liu S, et al. Effects of chitosan-oligosaccharides on growth performance, digestive enzyme and intestinal bacterial flora of of tiger puffer (Takifugu rubripes Temminck et Schlegel, 1850). J. Appl. Ichthyol. 2017;33:458-467.

[10] Tufan T, Arslan C, Sari M, Önk K, Deprem T, Çelik E. Effects of chitosan oligosaccharides addition to japanese quail's diets on growth, carcass traits, liver and intestinal histology, and intestinal microflora. Kafkas Univ. Vet. Fak. Derg. 2015;21:665-671.

[11] Wan J, Jiang F, Xu QS, Chen DW, Yu B, Huang ZQ, et al. New insights into the role of chitosan oligosaccharide in enhancing growth performance, antioxidant capacity, immunity and intestinal development of weaned pigs. RSC Adv. 2017;7:96699679.

[12] Wang Y, Xu W, Zuo R, Zhou H, Bai Y, Mai K, et al. Effect of dietary chitosan oligosaccharide complex with Ce (IV) on growth, immunity and disease resistance against Vibrio splendidus of sea cucumber, Apostichopus japonicas. Aquac. Res. 2017;48:1158-116.

[13] Zhang BZ. Dietary chitosan oligosaccharides modulate the growth, intestine digestive enzymes, body composition and nonspecific immunity of loach Paramisgurnus dabryanus. Fish. Shellfish Immunol. 
[14] Wu SJ. Preparation of water soluble chitosan by hydrolysis with commercial a-amylase containing chitosanase activity. Food Chem. 2011;128:769-772.

[15] Fernandez-Alarcon MF, Trottier N, Steibel JP, Lunedo R, Campos DMB, Santana AM, et al. Interference of age and supplementation of direct-fed microbial and essential oil in the activity of digestive enzymes and expression of genes related to transport and digestion of carbohydrates and proteins in the small intestine of broilers. Poult. Sci. 2017;96:2920-2930.

[16] Mao YM. Modulation of the growth performance, meat composition, oxidative status and immunity of broilers by dietary fulvic acids. Poultry Sci. 98 (2019) DOI: 10.3382/ps/pez281.

[17] Gong L, Wang B, Mei X, Xu H, Qin Y, Li W, et al. Effects of three probiotic Bacillus on growth performance, digestive enzyme activities, antioxidative capacity, serum immunity, and biochemical parameters in broilers. Anim. Sci. J. 2018;89:561-1571.

[18] Chen L, Feng L, Jiang WD, Jiang J, Wu P, Zhao J, et al. Dietary riboflavin deficiency decreases immunity and antioxidant capacity, and changes tight junction proteins and related signaling molecules mRNA expression in the gills of young grass carp (Ctenopharyngodon idella). Fish. Shellfish Immunol. 2015;45:307-320.

\section{Tables}

Due to technical limitations, Tables 1 - 6 are only available for download from the Supplementary Files section.

\section{Supplementary Files}

This is a list of supplementary files associated with this preprint. Click to download.

- Tables.docx 